\title{
Evaluating the initial impact of the revised Special Supplemental Nutrition Program for Women, Infants, and Children (WIC) food packages on dietary intake and home food availability in African-American and Hispanic families
}

\author{
Angela M Odoms-Young ${ }^{1, *}$, Angela Kong ${ }^{2}$, Linda A Schiffer ${ }^{3}$, Summer J Porter ${ }^{1}$, \\ Lara Blumstein ${ }^{3}$, Stephanie Bess ${ }^{4}$, Michael L Berbaum ${ }^{5}$ and Marian L Fitzgibbon ${ }^{3,5,6}$ \\ 'Department of Kinesiology and Nutrition, University of Illinois at Chicago, College of Applied Health Sciences, \\ 1919 West Taylor Street, M/C 517, Chicago, IL 60612, USA: ${ }^{2}$ Cancer Education and Career Development \\ Program, University of Illinois at Chicago, Chicago, IL, USA: ${ }^{3}$ Department of Medicine, University of Illinois at \\ Chicago, Chicago, IL, USA: ${ }^{4}$ WIC Nutrition Services, Illinois Department of Human Services, Springfield, IL, \\ USA: ${ }^{5}$ Institute for Health Research and Policy, University of Illinois at Chicago, Chicago, IL, USA: ${ }^{6}$ School of \\ Public Health, University of Illinois at Chicago, Chicago, IL, USA
}

Submitted 15 August 2012: Final revision received 22 January 2013: Accepted 24 January 2013: First published online 2 April 2013

\begin{abstract}
Objective: The present study assessed the impact of the 2009 food packages mandated by the Special Supplemental Nutrition Program for Women, Infants, and Children (WIC) on dietary intake and home food availability in low-income African-American and Hispanic parent/child dyads.

Design: A natural experiment was conducted to assess if the revised WIC food package altered dietary intake, home food availability, weight and various lifestyle measures immediately (6 months) following policy implementation.

Setting: Twelve WIC clinics in Chicago, IL, USA.

Subjects: Two hundred and seventy-three Hispanic and African-American children aged 2-3 years, enrolled in WIC, and their mothers.

Results: Six months after the WIC food package revisions were implemented, we observed modest changes in dietary intake. Fruit consumption increased among Hispanic mothers (mean $=0.33$ servings $/ \mathrm{d}, P=0.04$ ) and low-fat dairy intake increased among Hispanic mothers $(0 \cdot 21$ servings/d, $P=0 \cdot 02)$, Hispanic children $(0.34$ servings $/ \mathrm{d}, P<0 \cdot 001)$ and African-American children $(0.24$ servings $/ \mathrm{d}$, $P=0 \cdot 02$ ). Home food availability of low-fat dairy and whole grains also increased. Dietary changes, however, varied by racial/ethnic group. Changes in home food availability were not significantly correlated with changes in diet. Conclusions: The WIC food package revisions are one of the first efforts to modify the nutrition guidelines that govern foods provided in a federal food and nutrition assistance programme. It will be important to examine the longer-term impact of these changes on dietary intake and weight status.
\end{abstract}

Keywords Dietary behaviours Minority groups Food assistance Nutrition policy Obesity
The dramatic increase in overweight and obesity in the USA over the past several decades, particularly among children $^{(1)}$, has challenged researchers, clinicians and public health advocates to develop effective populationlevel obesity-prevention strategies ${ }^{(2)}$. While the development of obesity is influenced by multiple factors, dietary patterns clearly play a role ${ }^{(3)}$. Recently, obesity-prevention efforts in the USA have focused on developing nutrition policies to both promote awareness and ensure that at-risk populations, particularly low-income and minority children, have access to nutrient-dense foods ${ }^{(4)}$. As a result, much interest has been placed on modifying food benefits in federal nutrition assistance programmes ${ }^{(5)}$. One of the largest assistance programmes in the USA, the Special Supplemental Nutrition Program for Women, Infants, and Children (WIC), was created to safeguard the health of low-income women, infants and children up to the age of 5 years. In addition to nutrition education and medical/ social service referrals, the WIC programme provides a supplemental food package tailored to meet individual nutrient requirements. In December 2007, programme regulations governing the WIC food packages were revised to better reflect advances in nutrition science and current dietary recommendations and to address the high 
prevalence of obesity among WIC participants. Revisions offered a wider variety of foods, including fruits and vegetables and whole grains, and enabled WIC state agencies greater flexibility in prescribing foods that accommodate cultural food preferences ${ }^{(6)}$. Specific revisions in the food packages included a reduction in the fat content of milk, whole-grain options (including brown rice, oatmeal, corn tortillas and whole-wheat bread) and a monthly fruit and vegetable voucher ${ }^{(7)}$. The changes went into effect nationwide in October 2009.

Examining the impact of these revisions could have important implications for understanding the role of government assistance programmes and subsidies for nutrient-dense foods on health behaviours and obesity outcomes in low-income and minority populations. WIC is a central component of the American food and nutrition assistance system, serving approximately $9 \cdot 3$ million infants, children and pregnant/postpartum women across all fifty states, the District of Columbia, Indian Tribal Organizations, Guam, American Samoa, and the Commonwealth Islands of the Northern Marianas, Puerto Rico and the Virgin Islands ${ }^{(8)}$. Almost half of all infants and about $30 \%$ of all children $1-4$ years of age in the USA participate in the programme ${ }^{(8,9)}$. In addition, a high percentage of the children served by the WIC programme are Hispanic/Latino (50\%) and African-American $(20 \%)^{(10)}$. The food package revisions in WIC could be instrumental in establishing the foundation for future modifications in other food assistance programmes. Current studies have examined the impact of the revised WIC food packages on healthy food availability ${ }^{(11)}$, food access ${ }^{(12)}$, vendor perceptions $^{(13-15)}$ and breast-feeding ${ }^{(16)}$. However, research examining the impact of the revised WIC food packages on the dietary intake of WIC participants is limited ${ }^{(17)}$. The purpose of the present study was to examine whether home food availability and dietary intake changed among children participating in WIC and their primary caregivers six months following the changes in the WIC food package policy. In the initial six months of the food package revisions, we expected to observe a reduction in the consumption of whole milk and an increase in the consumption of reduced-fat milk, fruits, vegetables and whole grains.

\section{Methods}

\section{Design and setting}

Prior to the WIC food package revisions (summer 2009), 398 parent/child dyads were recruited from twelve WIC clinics in Chicago to participate in the Chicago Family Food Survey, a cross-sectional survey of dietary intake, home food availability and various lifestyle measures ${ }^{(18)}$. That study provided baseline data for a natural experiment examining psychosocial, behavioural and environmental determinants of dietary practices and weight status in WIC families six, twelve and eighteen months after the food package revisions. Changes in diet and home food availability were assessed approximately 6 months after the WIC food package changes went into effect (winter/spring 2010).

\section{Participants and eligibility}

Parent/child dyads were eligible for the original crosssectional study if the child was enrolled in WIC, if the child was between 2 and $3 \cdot 5$ years old, and if the parent/ guardian was fluent in English or Spanish. The age range was chosen to ensure that the children would be eating solid food and that they would still be eligible for WIC $(<5$ years old $)$ at the 18 -month visit. Diet and home food availability were expected to differ by parent's gender and race/ethnicity; however, we did not have enough parents who were male or non-Hispanic white to analyse these groups separately. Therefore, only dyads with a female parent and identified as either Hispanic or AfricanAmerican were included in the current analyses. Of the 295 dyads who completed the first (6-month) interview of this natural experiment, three were excluded because the guardianship of the child had changed and a different parent was interviewed at the 6-month visit, ten were excluded because the parent did not identify as AfricanAmerican or Hispanic and nine were excluded because the parent was male, leaving 143 Hispanic and 130 AfricanAmerican dyads ( $n$ 273). All of the Hispanic female parents/ guardians and most (92\%) of the African-American female parents/guardians included in these analyses were the children's mothers, so they are referred to as 'mothers' in this article.

\section{Measures}

Trained interviewers administered all questionnaires. All Hispanic participants were interviewed by bilingual interviewers in the language of their choice.

\section{Sociodemographic data}

Mothers completed a sociodemographic questionnaire at baseline, including questions on age, race/ethnicity, education, income, participation in food assistance programmes and the number of women (pregnant, breastfeeding or postpartum) and children (infants, children aged $1-<2$ years, children aged $2-5$ years) participating in WIC in their household.

\section{Acculturation}

At baseline, mothers who identified themselves as Hispanic/ Latina completed a four-item acculturation questionnaire ${ }^{(19)}$. The acculturation score was the mean of the four responses, ranging from 1 (least acculturated) to 5 (most acculturated). They also reported where they were born and how many years they had lived in the USA.

\section{Anthropometric variables}

Children's height and weight were measured at all visits. Mothers' height and weight were not measured at the 
baseline or 6-month visit, although they were measured at later visits. Height was measured using a Seca 214 portable stadiometer (Seca, Hanover, MD, USA). Weight was measured using a Tanita BWB-800 digital scale (Tanita Corporation of America, Inc., Arlington Heights, IL, USA). Participants removed their shoes and any heavy outer clothing for the anthropometric measurements. Both height and weight were measured twice, to the nearest $0 \cdot 1 \mathrm{~cm}$ and $0 \cdot 1 \mathrm{~kg}$, respectively. If the two height measurements were more than $0.5 \mathrm{~cm}$ apart or if the two weight measurements were more than $0.2 \mathrm{~kg}$ apart, a third measurement was taken. The mean of the two closest measurements was used for analysis. BMI was computed from height and weight, and BMI $Z$-scores and BMI percentiles for age and sex were calculated using a SAS program developed by the Centers for Disease Control and Prevention ${ }^{(20)}$.

\section{Food security}

Food security was assessed using the six-item short form of the US Household Food Security Survey Module ${ }^{(21)}$. Items included: 'The food that we bought just didn't last and we didn't have money to get more' and 'In the last 12 months, were you ever hungry but didn't eat because there wasn't enough money for food?' Parents who gave an affirmative response to zero or one items were scored as having high or marginal food security; those with two to four affirmative responses were scored as low; those with five or six affirmative responses were scored as very low. High and marginal food security were combined in a single category because the short form is unable to distinguish between high and marginal food security ${ }^{(22)}$.

\section{Dietary intake}

At each visit, a $24 \mathrm{~h}$ dietary recall was collected for each mother and child, using a multiple-pass approach ${ }^{(23)}$. Recalls were conducted by trained interviewers with backgrounds in nutrition/dietetics, public health and psychology. The mother was asked to report all foods and beverages she and her child had consumed in the $24 \mathrm{~h}$ period ending the previous midnight, including the time and type of meal, portions consumed, and details about how the food was prepared or where it was purchased (e.g. fast food), if appropriate. Booklets showing standard food measurements were used to improve accuracy of portion size recall.

The dietary intake data were processed using the Nutrition Data System for Research (NDS-R) software version 2009, developed by Nutrition Coordinating Center, University of Minnesota, Minneapolis, MN, USA. Foods with missing amounts that could not be resolved by deferring to NDS-R data-entry rules ${ }^{(24)}$ were imputed. Deriving imputed values from within this data set was not possible due to sample size; therefore, amounts based on the 1994-96 Continuing Survey of Food Intakes by Individuals ${ }^{(25)}$ provided the estimates (i.e. median portions by age and gender) for foods with missing values.
The amount consumed was estimated for one or more food items for nineteen ( $8 \%$ ) of the 253 mothers' records at baseline and two (1\%) at 6 months, and for twenty (9\%) of the 211 children's records at baseline and four (2\%) at 6 months. Dietary recalls with one or more missing main meals (i.e. breakfast, lunch or dinner) were considered incomplete and were excluded from analyses of dietary intake. Three mothers and sixty-two children were excluded from the dietary analyses because of an incomplete record at baseline or follow-up. Also, seventeen mothers who reported daily energy intake $<2092 \mathrm{~kJ}$ or $>20920 \mathrm{~kJ}$ ( $<500 \mathrm{kcal}$ or $>5000 \mathrm{kcal})$ at baseline or followup were excluded from the dietary analyses ${ }^{(26)}$.

The food group variables created by NDS-R were used to calculate consumption of fruit, $100 \%$ fruit juice, vegetables, milk, sweetened beverages and whole grains. The fruit variable included citrus and non-citrus fruits and excluded juices, avocado, fried fruits and fruit-based savoury snacks. The vegetable variable included all vegetable food group variables, plus avocado (i.e. dark green and deep yellow vegetables, tomatoes, white potatoes and other starchy vegetables, legumes, fried potatoes, other fried vegetables, vegetable juice, other vegetables). We also conducted a secondary analysis excluding fried potatoes and other fried vegetables. The sweetened beverage variable included sweetened soft drinks and fruit drinks, sweetened tea, coffee, coffee substitutes and water, and sweetened non-dairy supplements including sports drinks. The whole grain variable included whole grains, flours, and mixes, breads (including tortillas), crackers, pasta, cereal, baked goods, chips, snack bars and popcorn. A food was categorized as 'whole grain' if a whole grain ingredient was the first ingredient on the food label. In addition, foods categorized as 'some whole grain' were included in the summary variable with a weighting of $0 \cdot 5^{(27)}$. Serving sizes for the food group variables were based on the recommendations made by the Dietary Guidelines for Americans $2005^{(24,28)}$. For foods not covered, Food and Drug Administration serving sizes were used (NDS-R Manual $2009^{(24)}$, Appendix 10).

\section{Home food availability}

Home food availability was measured using a modified version of the measure reported in Cullen et al. ${ }^{(29)}$. The questionnaire consisted of a list of foods, including twentyfive fruits (fresh, frozen or canned, not including juices), four types of $100 \%$ fruit juice (apple, grape, orange, other), twenty-five vegetables (fresh, frozen or canned), milk (whole, 2\%, 1\%, skimmed or fat-free) and three of the whole-grain items offered in the new WIC food packages (whole-grain bread, corn tortillas and brown rice) in Illinois. Mothers were asked to report whether each food was available in their home in the past week. Summary variables were created by calculating the number of fruits, juices, vegetables and whole grains available in the home in the past week. 
Table 1 Baseline characteristics of the study sample: mothers and their 2-3-year-old children enrolled in WIC, Chicago, IL, USA, 2009

\begin{tabular}{|c|c|c|c|c|}
\hline & \multicolumn{2}{|c|}{ Hispanic } & \multicolumn{2}{|c|}{ African-American } \\
\hline & Mean or $n$ & SD or \% & Mean or $n$ & SD or \% \\
\hline \multicolumn{5}{|l|}{ Mothers } \\
\hline \multicolumn{5}{|l|}{ Relationship to child* } \\
\hline Mother & 143 & 100 & 120 & 92 \\
\hline Other & 0 & 0 & $10 \S$ & 8 \\
\hline Age (years), mean and SD & $29 \cdot 3$ & $5 \cdot 8$ & $30 \cdot 2$ & $9 \cdot 4$ \\
\hline Education (years), mean and SD & $11 \cdot 0$ & $2 \cdot 4$ & $12 \cdot 3$ & $1 \cdot 7$ \\
\hline Married/living with partner* & 106 & 75 & 24 & 18 \\
\hline Employed full-time ${ }^{*}$ & 21 & 15 & 21 & 16 \\
\hline Owns home* & 14 & 10 & 6 & 5 \\
\hline Owns or leases car* & 67 & 48 & 43 & 33 \\
\hline Children $<18$ years in household, mean and SD & $2 \cdot 5$ & $1 \cdot 2$ & $2 \cdot 6$ & $1 \cdot 4$ \\
\hline Other adults in household, mean and SD & $1 \cdot 3$ & $1 \cdot 2$ & $1 \cdot 1$ & $1 \cdot 1$ \\
\hline \multicolumn{5}{|l|}{ Fruit and vegetable voucher amount per household ${ }^{*}$} \\
\hline \$US 6/month & 59 & 41 & 62 & 48 \\
\hline \$US $12 /$ month & 39 & 27 & 38 & 29 \\
\hline \$US $14 /$ month & 22 & 15 & 11 & 8 \\
\hline \$US $18 /$ month & 7 & 5 & 7 & 5 \\
\hline$\geq \$$ US $20 /$ month & 16 & 11 & 12 & 9 \\
\hline SNAP (food stamps) in last 6 months* & 104 & 73 & 109 & 84 \\
\hline \multicolumn{5}{|l|}{ Food security* } \\
\hline High or marginal & 62 & 43 & 75 & 58 \\
\hline Low & 61 & 43 & 39 & 30 \\
\hline Very low & 20 & 14 & 16 & 12 \\
\hline Acculturation $\ddagger$, mean and SD & $2 \cdot 0$ & $1 \cdot 2$ & & \\
\hline Born in USA* & 37 & 26 & & \\
\hline \multicolumn{5}{|l|}{ Children } \\
\hline Female $^{\star}$ & 71 & 50 & 63 & 48 \\
\hline Age (months), mean and SD & $32 \cdot 9$ & $6 \cdot 0$ & $33 \cdot 1$ & $5 \cdot 6$ \\
\hline $\mathrm{BMI}\left(\mathrm{kg} / \mathrm{m}^{2}\right)$, mean and SD & $17 \cdot 4$ & $2 \cdot 1$ & $16 \cdot 8$ & $1 \cdot 7$ \\
\hline BMI $Z$-score, mean and SD & $0 \cdot 8$ & $1 \cdot 2$ & $0 \cdot 4$ & $1 \cdot 3$ \\
\hline \multicolumn{5}{|l|}{ BMI percentile* } \\
\hline$<5$ th (underweight) & 4 & 3 & 7 & 6 \\
\hline 5 th $-<85$ th (normal weight) & 78 & 57 & 79 & 62 \\
\hline 85th- $<95$ th (overweight) & 25 & 18 & 19 & 15 \\
\hline$\geq 95$ th (obese) & 30 & 22 & 22 & 17 \\
\hline Weight $(\mathrm{kg})$, mean and SD & $14 \cdot 7$ & $2 \cdot 7$ & $14 \cdot 5$ & $2 \cdot 1$ \\
\hline Height $(\mathrm{cm})$, mean and SD & $91 \cdot 8$ & $5 \cdot 3$ & $92 \cdot 6$ & $5 \cdot 2$ \\
\hline
\end{tabular}

WIC, Special Supplemental Nutrition Program for Women, Infants, and Children; SNAP, Supplemental Nutrition Assistance Program $n 143$ for Hispanic participants and $n 130$ for African-American participants. Numbers are slightly lower for some variables due to missing data. *Values presented are $n$ and \%.

t\$US 8/month for each adult enrolled in WIC, \$US 6/month for each child aged $\geq 1$ year.

‡From Marin scale; scores can range from 1 (least acculturated) to 5 (most acculturated).

$\S$ Four grandmothers, one great-grandmother, five foster mothers.

\section{Statistical analyses}

We have previously shown that Hispanic and AfricanAmerican participants in our sample had significantly different dietary patterns, as well as some significant demographic differences ${ }^{(18)}$. Therefore, we conducted separate analyses for Hispanic and African-American participants, as well as for mothers and children. Paired $t$ tests and McNemar's test were used to test for significant changes in BMI, diet and home food availability from baseline to the 6-month visit. Spearman correlation coefficients were used to test for associations between diet and home food availability at baseline, changes in mothers' and children's dietary intake, and changes in diet and home food availability.

\section{Results}

Baseline characteristics of mothers and children are shown in Table 1 . The average level of education was slightly lower among Hispanic mothers than AfricanAmerican mothers (mean 11.0 v. 12.3 years); $50 \%$ of Hispanic mothers and $80 \%$ of African-American mothers were high-school graduates. Few of the mothers were employed full-time.

Among the Hispanic mothers, 114 (80\%) identified as Mexican, Mexican-American or Chicano; thirteen (9\%) as Puerto Rican; and sixteen (11\%) as part of another subgroup. The mean level of acculturation was relatively low (2.0 on a scale of $1-5)$ and the majority of Hispanic mothers ( $n 106,74 \%)$ were born outside the USA: ninetytwo (64\%) in Mexico and fourteen (10\%) elsewhere. On average, Hispanic mothers born outside the USA had been in the USA for $10 \cdot 3(5 \cdot 4)$ years, with a range from 3 to 27 years. We did not request information about African-American subgroups.

Obesity was slightly more prevalent among the children in this sample than in national samples of Hispanic and non-Hispanic black children. Among the Hispanic children, 
$21 \cdot 9 \%$ were obese compared with $14 \cdot 2 \%$ (95\% CI $10 \cdot 3$, $18 \cdot 2 \%$ ) in the National Health and Nutrition Examination Survey (NHANES) 2007-2008 (representative sample of 2-5-year-old Hispanic children) and $18.5 \%$ in the Pediatric Nutrition Surveillance System (PedNSS) sample (lowincome Hispanic children specifically, ages 24-59 months). Similarly, $17 \cdot 3 \%$ of African-American children were obese compared with $11 \cdot 4 \%(95 \%$ CI $7 \cdot 1,15 \cdot 8 \%)$ in the NHANES and $11 \cdot 8 \%$ in the PedNSS sample ${ }^{(30-32)}$.

\section{Dietary changes}

Table 2 shows dietary changes in Hispanic and AfricanAmerican mothers and children between the baseline and 6-month visits. Energy intake did not change significantly among mothers, but it did increase in AfricanAmerican children (mean change $=728 \mathrm{~kJ}, P=0 \cdot 006$ ) and approached significance among Hispanic children (mean change $=378 \mathrm{~kJ}, \quad P=0 \cdot 07)$. There was no significant change in fat intake as a percentage of energy (\%E) in any group, although the change approached significance among Hispanic mothers (mean change $=-1 \cdot 86 \% \mathrm{E}$, $P=0 \cdot 06$ ). Mean fat consumption as a percentage of energy for Hispanic mothers and children and for AfricanAmerican children at 6 months fell within the range recommended by the Dietary Guidelines for Americans. However, the mean fat intake at 6 months for AfricanAmerican mothers $(38 \cdot 1 \% \mathrm{E})$ remained higher than the recommended intake of $20-35 \% \mathrm{E}$.

Consumption of saturated fat as a percentage of energy was significantly reduced at 6 months in Hispanic mothers (mean change $=-0.95 \% \mathrm{E}, P=0.03$ ) and children $(-1 \cdot 18 \% \mathrm{E}, P=0 \cdot 01)$. At 6 months, mean consumption of saturated fats was close to the levels recommended by national guidelines $(<10 \% \mathrm{E})$ for Hispanic mothers and children $^{(33)}$. Saturated fat intake did not change significantly for African-American mothers or children. On average, both consumed more than the recommended amount of saturated fat at both baseline and 6 months. This decrease in percentage of energy from saturated fat for both Hispanic mothers and children brings them both closer to meeting current recommendations. The percentage of energy from saturated fat remained stable for both African-American mothers and children who were still above the recommended level of $<10 \% \mathrm{E}$ from saturated fat.

Dietary fibre consumption increased significantly only among Hispanic children (mean change $=1 \cdot 00 \mathrm{~g} / 4184 \mathrm{~kJ}$ (1000 kcal), $P=0 \cdot 05)$. In all groups, mean fibre intake was below the recommended level of $14 \mathrm{~g} / 4184 \mathrm{~kJ}$ (1000 kcal) at 6 months. However, Hispanic mothers and children consumed more fibre than their African-American counterparts.

Among Hispanic mothers, fruit consumption increased by a modest but statistically significant amount (mean change $=0.33$ servings $/ \mathrm{d}, P=0 \cdot 04)$ and consumption of fruit juice fell $(-0 \cdot 45$ servings $/ \mathrm{d}, P=0 \cdot 02)$. However, there was no significant change in fruit or juice consumption for either Hispanic or African-American children or AfricanAmerican mothers. Vegetable intake did not change significantly for mothers or children. According to MyPlate guidelines $^{(34)}$, children aged 2-3 years should consume at least 1 cup of fruit (including 100\% juice) and 1 cup of vegetables each day, which is equivalent to two servings of fruits and vegetables per day, respectively ${ }^{(28)}$. Adult women (19-50 years) should eat at least 1.5-2 cups of fruit and 2.5 cups of vegetables per day, which is equivalent to three to four servings of fruits and five servings of vegetables ${ }^{(28)}$. Neither adults nor children in any group met recommendations for fruits and vegetables. However, Hispanic children did come close to fruit recommendations of 2 servings/d ( 1.9 servings/d).

Patterns of milk consumption changed significantly. Children and Hispanic mothers drank more reduced-fat, low-fat and non-fat milk, and less whole milk, at 6 months than at baseline. Notably, African-American mothers also drank somewhat less whole milk at 6 months than at baseline (mean change $=-0 \cdot 11$ servings $/ \mathrm{d}, P=0 \cdot 02$ ) but did not significantly increase their consumption of reduced-fat, low-fat and non-fat milk. On average, AfricanAmerican mothers drank relatively little milk: mean total milk consumption $=0.4(\mathrm{sD} 0.9)$ servings $/ \mathrm{d}$ at baseline and $0 \cdot 4$ (SD 0.5) servings/d at 6 months. As expected, there was a significant $(P<0 \cdot 001)$ negative correlation between change in whole milk intake and change in intake of $2 \%$, $1 \%$ or non-fat milk for children and Hispanic mothers: Spearman $r_{\mathrm{S}}=-0.55$ for Hispanic children, -0.39 for African-American children and -0.39 for Hispanic mothers.

Consumption of sweetened beverages (sweetened soft drinks, fruit drinks, tea, coffee, coffee substitutes, non-dairy supplements) did not change significantly in mothers or Hispanic children but increased by 0.27 servings/d in African-American children $(P=0 \cdot 03)$.

Consumption of whole grains increased modestly but significantly among Hispanic children (mean change $=0.30$ servings/d, $P=0.02$ ) but not among mothers or AfricanAmerican children.

Dietary changes in mothers and their children were significantly positively correlated (Table 3). Changes in energy, fat and saturated fat were positively correlated for both Hispanic and African-American dyads. However, changes in fibre intake were significantly correlated for Hispanic dyads but not for African-American dyads. Changes in consumption of fruit, vegetables, reduced-fat milk, whole milk and whole grains were also positively correlated. Change in sweetened beverage consumption was significantly correlated in African-American dyads ( $r_{\mathrm{s}}=0 \cdot 32, P=0 \cdot 003$ ), but not in Hispanic dyads.

Among Hispanic mothers, acculturation was negatively correlated with change in fruit consumption $\left(r_{\mathrm{s}}=-0 \cdot 20\right.$, $P=0 \cdot 03, n$ 113). There was no significant association between acculturation and changes in children's fruit consumption or in mothers' or children's juice, vegetable, milk or sweetened beverage consumption (data not shown). 
Table 2 Diet at baseline and at 6 months after WIC food package change: mothers and their 2-3-year-old children enrolled in WIC, Chicago, IL, USA, 2009-2010

\begin{tabular}{|c|c|c|c|c|c|c|c|c|c|c|c|c|c|c|}
\hline \multirow[b]{3}{*}{ Dietary intake ( $24 \mathrm{~h}$ recall) } & \multicolumn{7}{|c|}{ Hispanic } & \multicolumn{7}{|c|}{ African-American } \\
\hline & \multicolumn{2}{|c|}{ Baseline } & \multicolumn{2}{|c|}{6 months } & \multicolumn{2}{|c|}{ Change } & \multirow[b]{2}{*}{$P^{*}$} & \multicolumn{2}{|c|}{ Baseline } & \multicolumn{2}{|c|}{6 months } & \multicolumn{2}{|c|}{ Change } & \multirow[b]{2}{*}{$P^{\star}$} \\
\hline & Mean & SD & Mean & SD & Mean & SD & & Mean & SD & Mean & SD & Mean & SD & \\
\hline Mothers & $n 132$ & & & & & & & $n 121$ & & & & & & \\
\hline Energy (kJ/d) & 6480 & 2431 & 6440 & 2692 & -39 & 3113 & 0.88 & 7848 & 3825 & 7752 & 3351 & -96 & 4094 & $0 \cdot 80$ \\
\hline Energy $(\mathrm{kcal} / \mathrm{d})$ & 1549 & 581 & 1539 & 643 & -9 & 744 & 0.88 & 1876 & 914 & 1853 & 801 & -23 & 978 & $0 \cdot 80$ \\
\hline Fat $(\% \mathrm{E})$ & $31 \cdot 3$ & $9 \cdot 1$ & $29 \cdot 4$ & $9 \cdot 0$ & $-1 \cdot 86$ & $11 \cdot 43$ & 0.06 & $37 \cdot 9$ & 8.9 & $38 \cdot 1$ & $9 \cdot 3$ & 0.24 & $12 \cdot 02$ & 0.83 \\
\hline Saturated fat $(\% \mathrm{E})$ & $10 \cdot 9$ & $4 \cdot 1$ & $10 \cdot 0$ & $3 \cdot 6$ & -0.95 & $5 \cdot 11$ & 0.03 & $12 \cdot 7$ & $4 \cdot 0$ & $13 \cdot 0$ & $4 \cdot 6$ & $0 \cdot 35$ & $5 \cdot 77$ & 0.51 \\
\hline Fibre (g/4184 kJ (1000 kcal)) & $10 \cdot 6$ & $5 \cdot 6$ & $11 \cdot 2$ & $5 \cdot 4$ & 0.57 & $6 \cdot 25$ & 0.30 & $5 \cdot 7$ & $3 \cdot 0$ & $6 \cdot 0$ & $2 \cdot 9$ & $0 \cdot 25$ & $4 \cdot 01$ & 0.49 \\
\hline Fruitt (servings/d) & 0.8 & $1 \cdot 2$ & $1 \cdot 1$ & 1.5 & 0.33 & 1.88 & 0.04 & 0.2 & 0.8 & 0.4 & $1 \cdot 4$ & 0.21 & $1 \cdot 61$ & $0 \cdot 15$ \\
\hline $100 \%$ fruit juiceł (servings/d) & $1 \cdot 0$ & 1.5 & 0.5 & $1 \cdot 9$ & -0.45 & $2 \cdot 16$ & 0.02 & $0 \cdot 7$ & $1 \cdot 3$ & $0 \cdot 7$ & $1 \cdot 4$ & -0.04 & $1 \cdot 42$ & $0 \cdot 77$ \\
\hline Vegetables $\$$ (servings/d) & $2 \cdot 3$ & $1 \cdot 7$ & $2 \cdot 4$ & $1 \cdot 8$ & 0.09 & $2 \cdot 40$ & 0.66 & $1 \cdot 7$ & $1 \cdot 8$ & $1 \cdot 9$ & $1 \cdot 8$ & 0.15 & $2 \cdot 55$ & 0.53 \\
\hline Milk, $2 \%, 1 \%$ non-fat $\|($ servings $/ d)$ & 0.6 & 0.8 & $0 \cdot 8$ & 0.9 & 0.21 & 1.03 & 0.02 & 0.2 & 0.8 & 0.3 & 0.5 & 0.04 & 0.92 & 0.66 \\
\hline Milk, whole\|l (servings/d) & $0 \cdot 3$ & 0.7 & $0 \cdot 1$ & $0 \cdot 3$ & $-0 \cdot 18$ & 0.68 & 0.004 & 0.2 & 0.5 & $0 \cdot 1$ & $0 \cdot 3$ & $-0 \cdot 11$ & 0.55 & 0.02 \\
\hline Sweetened beverages (servings/d) & 0.9 & $1 \cdot 2$ & $1 \cdot 0$ & $1 \cdot 4$ & 0.03 & 1.52 & 0.83 & $1 \cdot 8$ & $1 \cdot 8$ & $2 \cdot 1$ & $1 \cdot 7$ & 0.28 & $1 \cdot 90$ & $0 \cdot 11$ \\
\hline Whole grains ${ }^{* *}$ (servings/d) & $2 \cdot 4$ & $2 \cdot 3$ & $2 \cdot 8$ & $2 \cdot 5$ & 0.35 & $2 \cdot 83$ & $0 \cdot 16$ & $1 \cdot 1$ & 1.9 & $1 \cdot 2$ & $1 \cdot 8$ & $0 \cdot 12$ & $2 \cdot 54$ & $0 \cdot 61$ \\
\hline Children & $n 121$ & & & & & & & $n 90$ & & & & & & \\
\hline Energy (kJ/d) & 4438 & 1772 & 4812 & 1798 & 378 & 2311 & 0.07 & 4712 & 2043 & 5440 & 2143 & 728 & 2449 & 0.006 \\
\hline Energy $(\mathrm{kcal} / \mathrm{d})$ & 1061 & 423 & 1151 & 430 & 90 & 552 & 0.07 & 1126 & 488 & 1300 & 512 & 174 & 585 & 0.006 \\
\hline Fat $(\% \mathrm{E})$ & $31 \cdot 2$ & $8 \cdot 4$ & $29 \cdot 7$ & $8 \cdot 7$ & $-1 \cdot 44$ & $10 \cdot 89$ & $0 \cdot 15$ & $35 \cdot 4$ & $8 \cdot 0$ & $36 \cdot 3$ & $7 \cdot 9$ & $0 \cdot 88$ & $10 \cdot 01$ & $0 \cdot 40$ \\
\hline Saturated fat $(\% \mathrm{E})$ & $12 \cdot 1$ & $3 \cdot 6$ & $10 \cdot 9$ & $3 \cdot 8$ & $-1 \cdot 18$ & 4.99 & 0.01 & $12 \cdot 6$ & $4 \cdot 1$ & $12 \cdot 2$ & $3 \cdot 3$ & -0.41 & $4 \cdot 44$ & 0.39 \\
\hline Fibre $(\mathrm{g} / 4184 \mathrm{~kJ}(1000 \mathrm{kcal}))$ & $8 \cdot 4$ & $4 \cdot 2$ & $9 \cdot 4$ & $5 \cdot 0$ & 1.00 & $5 \cdot 58$ & 0.05 & $6 \cdot 0$ & $2 \cdot 6$ & $6 \cdot 1$ & $2 \cdot 3$ & 0.12 & $3 \cdot 19$ & 0.72 \\
\hline Fruitt (servings/d) & $1 \cdot 0$ & 1.5 & $1 \cdot 1$ & $1 \cdot 4$ & $0 \cdot 12$ & $1 \cdot 86$ & 0.47 & $0 \cdot 4$ & 0.9 & 0.5 & $0 \cdot 8$ & 0.01 & $1 \cdot 11$ & 0.95 \\
\hline $100 \%$ fruit juiceł (servings/d) & $1 \cdot 0$ & $1 \cdot 2$ & 0.8 & $1 \cdot 1$ & $-0 \cdot 16$ & $1 \cdot 36$ & $0 \cdot 20$ & $1 \cdot 1$ & $1 \cdot 7$ & $1 \cdot 0$ & $1 \cdot 4$ & $-0 \cdot 10$ & $2 \cdot 05$ & 0.65 \\
\hline Vegetables $\$$ (servings/d) & $1 \cdot 1$ & $1 \cdot 1$ & $1 \cdot 3$ & $1 \cdot 6$ & $0 \cdot 25$ & 1.57 & 0.09 & $0 \cdot 8$ & $1 \cdot 0$ & $1 \cdot 0$ & $1 \cdot 0$ & 0.15 & $1 \cdot 31$ & 0.28 \\
\hline Milk, $2 \%, 1 \%$, non-fat\| (servings/d) & 0.7 & 0.9 & $1 \cdot 0$ & 0.8 & 0.34 & 1.05 & $<0.001$ & 0.4 & $0 \cdot 8$ & $0 \cdot 6$ & $0 \cdot 8$ & 0.24 & 0.98 & 0.02 \\
\hline Milk, whole\| (servings/d) & 0.5 & 0.7 & 0.2 & 0.5 & -0.33 & 0.88 & $<0.001$ & $0 \cdot 4$ & $0 \cdot 7$ & $0 \cdot 2$ & 0.5 & -0.24 & $0 \cdot 81$ & 0.007 \\
\hline Sweetened beverages (servings/d) & 0.4 & 0.6 & $0 . \overline{4}$ & $0 \cdot 6$ & 0.02 & 0.80 & 0.74 & $0 \cdot 6$ & $0 \cdot 8$ & $0 \cdot \overline{8}$ & $1 \cdot 2$ & 0.27 & $1 \cdot 21$ & 0.03 \\
\hline Whole grains ${ }^{\star \star}($ servings $/ \mathrm{d})$ & 0.9 & $1 \cdot 0$ & $1 \cdot 2$ & $1 \cdot 3$ & $0 \cdot 30$ & 1.41 & 0.02 & 0.7 & $1 \cdot 2$ & 0.8 & $1 \cdot 0$ & $0 \cdot 12$ & $1 \cdot 36$ & 0.42 \\
\hline
\end{tabular}

WIC, Special Supplemental Nutrition Program for Women, Infants, and Children; \%E, percentage of energy intake; NDS-R, Nutrition Data System for Research.

${ }^{*}$ From paired $t$-test.

tNDS-R fruit food groups, excluding juices, avocado, fried fruits and fruit-based savoury snacks. One serving is 1 medium piece of fruit, $1 / 4$ cup of dried fruit, $1 / 2$ cup of fresh, frozen, canned or cooked fruit (chopped or default form), or $1 / 2$ fresh grapefruit.

$\ddagger$ One serving is 4 fluid ounces.

\$ncludes all NDS-R vegetable food groups and avocado. One serving is 1 cup of raw leafy vegetables, $1 / 2$ cup of other cooked or raw vegetables, or $1 / 2$ cup of vegetable juice.

IOne serving is 1 cup.

- Includes sweetened soft drinks, fruit drinks, tea, coffee, coffee substitutes and water, and non-dairy supplements including sports drinks. One serving is 8 fluid ounces.

${ }^{*}$ Includes all NDS-R whole grain food groups plus 'some whole grain' food groups weighted by $0 \cdot 5$. One serving is 1 slice of bread ( $16 \mathrm{~g}$ of flour), 1 ounce of ready-to-eat cereal or $1 / 2$ cup of cooked cereal, rice or pasta. 
Table 3 Correlations between mothers' and children's dietary changes from baseline to 6 months: mothers and their 2-3-year-old children enrolled in WIC, Chicago, IL, USA, 2009-2010

\begin{tabular}{|c|c|c|c|c|}
\hline \multirow[b]{2}{*}{ Change } & \multicolumn{2}{|c|}{ Hispanic (n 113) } & \multicolumn{2}{|c|}{ African-American ( $n$ 84) } \\
\hline & $r_{\mathrm{S}}$ & $P$ & $r_{\mathrm{S}}$ & $P$ \\
\hline Energy $(\mathrm{kJ} / \mathrm{d})$ & $0 \cdot 21$ & 0.03 & 0.25 & 0.02 \\
\hline Fat $(\% \mathrm{E})$ & 0.27 & 0.004 & $0 \cdot 26$ & 0.02 \\
\hline Saturated fat (\%E) & $0 \cdot 27$ & 0.003 & 0.28 & 0.009 \\
\hline Fibre (g/4184 kJ (1000 kcal)) & $0 \cdot 22$ & 0.02 & $0 \cdot 19$ & 0.09 \\
\hline Fruit* (servings/d) & $0 \cdot 27$ & 0.004 & $0 \cdot 31$ & 0.004 \\
\hline $100 \%$ fruit juice (servings/d) & $0 \cdot 14$ & $0 \cdot 14$ & 0.26 & 0.02 \\
\hline Vegetablest (servings/d) & $0 \cdot 19$ & 0.05 & 0.44 & $<0.001$ \\
\hline Milk, $2 \%, 1 \%$, non-fat (servings/d) & 0.22 & 0.02 & 0.25 & 0.02 \\
\hline Milk, whole (servings/d) & 0.51 & $<0.001$ & $0 \cdot 28$ & 0.009 \\
\hline Sweetened beverages $\ddagger$ (servings/d) & $0 \cdot 10$ & $0 \cdot 28$ & 0.32 & 0.003 \\
\hline Whole grains $\S$ (servings/d) & $0 \cdot 28$ & 0.002 & 0.24 & 0.03 \\
\hline
\end{tabular}

WIC, Special Supplemental Nutrition Program for Women, Infants, and Children; \%E, percentage of energy intake; NDS-R, Nutrition Data System for Research.

*NDS-R fruit food groups, excluding juices, avocado, fried fruits and fruit-based savoury snacks.

tIncludes all NDS-R vegetable food groups and avocado.

flncludes sweetened soft drinks, fruit drinks, tea, coffee, coffee substitutes and water, and non-dairy supplements including sports drinks.

§Includes all NDS-R whole grain food groups plus 'some whole grain' food groups weighted by $0 \cdot 5$.

\section{Home food availability changes}

Changes in the number of types of fruits, juices, vegetables and whole-grain items available in the home six months after the food package change are shown in Table 4. At both visits, reported availability of fruits and vegetables was high. At baseline, Hispanic mothers reported that a mean of $12 \cdot 4$ types of fruit (from a list of twenty-five, not including juices) and 14.9 types of vegetables (from a list of twenty-five) were available in their homes in the past week, and African-American mothers reported 8.6 fruits and 11.5 vegetables. The reported number of fruits did not change significantly in either group at 6 months. The reported number of vegetables increased by 1.36 (SD 3.62) among African-American mothers $(P<0 \cdot 001)$ but did not change significantly among Hispanic mothers. The reported number of fruit juices in the home also increased among African-American mothers $(P<0 \cdot 001)$ but not among Hispanic mothers.

Both groups reported an increased number of wholegrain items (whole-grain bread, corn tortillas and brown rice) in the home at the 6 -month visit, from $1.9(0.7)$ at baseline to $2 \cdot 2(0 \cdot 7)$ at 6 months among Hispanic mothers and from $1.5(0.9)$ to $1.9(0.9)$ among African-American mothers (both $P<0 \cdot 001$ ). Both Hispanic and AfricanAmerican mothers were more likely to report that they had $2 \%, 1 \%$ or non-fat milk in the home $(P<0 \cdot 001)$ and less likely to report that they had whole milk in the home $(P<0 \cdot 001)$ at the 6-month visit than at baseline.

In general, changes in home food availability were not significantly correlated with changes in diet (Table 5). Changes in the number of $100 \%$ fruit juices in the home were weakly correlated with fruit juice consumption in Hispanic children $\left(r_{s}=0 \cdot 18, P=0 \cdot 05\right)$ but not in Hispanic mothers or African-American children or mothers. Similarly, the change in the number of vegetables in the home was significantly correlated with vegetable consumption in African-American mothers $\left(r_{s}=0 \cdot 22, P=0.04\right)$ but not in African-American children or Hispanic mothers or children.

\section{Discussion}

Implemented in 2009, the WIC food package revisions constitute one of the most significant efforts to modify the nutrition guidelines in a federal food and nutrition assistance programme. These revisions provide a unique opportunity to evaluate how revised polices in food and nutrition assistance impact dietary patterns and related health outcomes such as weight status in low-income children and their caregivers.

The current investigation focused on assessing the initial impact of the food package revisions in a sample of minority mother/child dyads, who make up a substantial percentage of the WIC population and who commonly are at risk for poor dietary intakes and overweight ${ }^{(8)}$. To date, there has only been only one other published study evaluating the impact of the revised WIC food package on dietary intake ${ }^{(17)}$. Whaley et al. conducted a study to assess dietary changes among WIC participants and parents/caregivers before and after the WIC food package revision. However, in contrast to the previous investigation, the current study is a natural experiment ( $v$. a crosssectional comparison) and we administered $24 \mathrm{~h}$ recalls to assess dietary intake ( $v$. survey items). We hypothesized that we would observe a decrease in whole milk consumption and an increase in low-fat milk consumption, as well as an increase in fruits, vegetables and whole grains. Our results suggest a significant decrease in whole milk consumption among all groups, as well as a significant increase in lower-fat milk consumption among all groups 


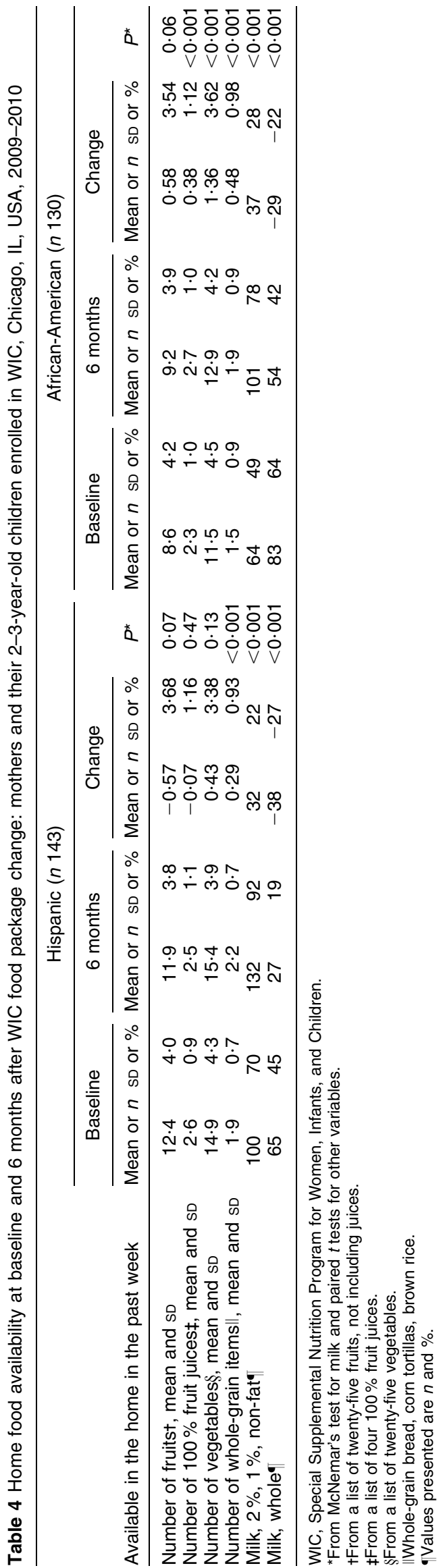

except African-American mothers. Substituting low-fat milk for whole milk could lower population-level saturated fat intake from $13 \cdot 3 \% \mathrm{E}$ to under $10 \% \mathrm{E}^{(17)}$. Subsequent evaluations of milk consumption at 12 and 18 months post-revision will demonstrate whether these changes persist and therefore have the potential to impact long-term weight trajectory. Among African-American mothers and children, we observed a small increase in sugar-sweetened beverage consumption; however, this was not statistically significant among mothers. Our study results suggest that changes in the WIC food package guidelines for milk may have the least effect on dietary fat intake and related health outcomes in African-American women. Similar to previous studies, milk intake for AfricanAmerican women was relatively low at both baseline and 6 months ${ }^{(35)}$. Other researchers have found an inverse association between consumption of sweetened beverages and low-fat milk in both African Americans and whites ${ }^{(35,36)}$. Low intake of dairy foods in African Americans has been associated with perceived and/or actual lactose intolerance $^{(37)}$. However, few studies have examined factors that contribute to acceptability of low-fat milk in African Americans ${ }^{(38)}$. Given the positive impact of dairy foods on health, this may be an important direction for future studies.

Since lower-income populations tend to consume fewer fruits and vegetables than those of higher income $^{(39)}$, the inclusion of a fruit/vegetable voucher was a highly anticipated change in the WIC supplemental food offerings ${ }^{(40)}$. Consumption of fruits and vegetables increased following the introduction of the cash-value vouchers, but only among Hispanic mothers. The reported intake of fruits and vegetables did not change significantly among African-American mothers and children and among Hispanic children. It may be that AfricanAmerican mothers used their WIC fruit/vegetable voucher and spent the money they would have spent on fruits and vegetables on different foods. In contrast, Hispanic mothers may have made additional purchases of fruit rather than vegetables, which translated into increased fruit consumption. Prior to the WIC policy change ${ }^{(41)}$, Herman and colleagues examined the effect of a \$US 40/ month fruit/vegetable subsidy on consumption of fruit and vegetables among primarily Hispanic postpartum WIC participants in Los Angeles, $\mathrm{CA}^{(5,41)}$. Women receiving the subsidy purchased a wide variety of fruits and vegetables for their families and significantly increased fruit and vegetable consumption compared with controls, both immediately following the intervention and at 6-month follow-up ${ }^{(41)}$. At the time of our study, the WIC food package included a \$US 6.00 monthly fruit/vegetable voucher for children and an \$US 8.00 monthly voucher for pregnant and postpartum women, which was increased to \$US $10 \cdot 00 /$ month in 2010 . The median voucher amount for the families in our study was \$US 12/ month. Results from Herman and colleagues suggest that a larger subsidy could have had a greater impact on 
Table 5 Correlations between dietary changes and changes in home food availability from baseline to 6 months: mothers and their 2-3-year-old children enrolled in WIC, Chicago, IL, USA, 2009-2010

\begin{tabular}{|c|c|c|c|c|}
\hline & \multicolumn{2}{|c|}{ Hispanic (n 113) } & \multicolumn{2}{|c|}{ African-American ( $n$ 84) } \\
\hline & $r_{\mathrm{S}}$ & $P$ & $r_{\mathrm{S}}$ & $P$ \\
\hline \multicolumn{5}{|l|}{ Mothers } \\
\hline Fruit* & $0 \cdot 12$ & $0 \cdot 19$ & $0 \cdot 12$ & 0.26 \\
\hline $100 \%$ fruit juicet & 0.07 & 0.48 & -0.03 & 0.78 \\
\hline Vegetables $\ddagger$ & 0.08 & $0 \cdot 40$ & 0.22 & 0.04 \\
\hline Whole grains $\S$ & -0.01 & 0.96 & 0.08 & 0.49 \\
\hline Whole grains and dietary fibrell & $0 \cdot 13$ & $0 \cdot 18$ & $0 \cdot 13$ & $0 \cdot 24$ \\
\hline \multicolumn{5}{|l|}{ Children } \\
\hline Fruit* & 0.09 & $0 \cdot 33$ & 0.03 & 0.78 \\
\hline $100 \%$ fruit juicet & $0 \cdot 18$ & 0.05 & 0.09 & 0.42 \\
\hline Vegetables $\ddagger$ & -0.05 & $0 \cdot 61$ & $0 \cdot 10$ & 0.39 \\
\hline Whole grains $\S$ & -0.05 & 0.56 & $-0 \cdot 10$ & 0.39 \\
\hline Whole grains and dietary fibrell & 0.13 & $0 \cdot 16$ & 0.03 & $0 \cdot 75$ \\
\hline
\end{tabular}

WIC, Special Supplemental Nutrition Program for Women, Infants, and Children.

${ }^{\star}$ Change in servings of fruit/d $v$. change in number of fruits in the home (list of twenty-five, excluding juices).

tChange in servings of $100 \%$ fruit juice/d $v$. change in number of fruit juices in the home (list of four).

$\ddagger$ Change in servings of vegetables/d $v$. change in number of vegetables in the home (list of twenty-five).

§Change in servings of whole grains/d $v$. change in number of whole-grain items in the home (list of three: whole-grain bread, corn tortillas, brown rice).

\|Change in dietary fibre intake $(\mathrm{g} / 4184 \mathrm{~kJ}(1000 \mathrm{kcal})) \mathrm{v}$. change in number of whole-grain items in the home (list of three: whole-grain bread, corn tortillas, brown rice).

dietary intake. In addition, in the previous study, women were also allowed to redeem their voucher at farmers' markets. Although this is allowed in some states, it was not allowed in our study area. Whaley et al. also reported a modest change in fruit and vegetable intake; however, a separate analysis by racial/ethnic subgroup was not conducted $^{(17)}$.

Regarding home food availability, mothers reported some changes in the availability of certain foods in the home, particularly whole grains and milk. Previous studies have emphasized the importance of the home environment in promoting positive dietary intake and healthy food preferences ${ }^{(42)}$. Nevertheless, changes in reported home food availability did not necessarily translate into changes in dietary intake. Changes in milk consumption were consistent with reported changes in home food availability, but despite the reported increase in availability of whole-grain foods, dietary fibre rose significantly only in Hispanic children. Similarly, AfricanAmerican mothers reported an increase in the number of vegetables in the home, but vegetable intake did not change significantly among either mothers or children. Also, there was no reported increase in the number of fruits in the homes of Hispanic families, but there was a significant increase in fruit consumption among Hispanic mothers. Increases in the availability of fruits and vegetables in the home have been shown to increase consumption $^{(43)}$, but the high reported availability of both fruits and vegetables in the homes of both groups at baseline and 6 months does not appear to have changed intake in our sample. It should be noted that the reported availability of fruits/vegetables in the homes of both ethnic groups, particularly in Hispanic households, may reflect limitations in the measure we used or socially desirable responses that have been noted in Hispanic populations ${ }^{(44)}$. It is also possible that the relatively low value of the fruit/vegetable vouchers was not sufficient to significantly increase home availability or consumption, particularly when participants may be using the vouchers to purchase fruits and vegetables previously purchased with other support. We will examine this possibility further in the final analysis of the full 18-month study.

\section{Conclusions}

There are limitations that need to be considered when interpreting our findings. The sample was recruited from a large urban city whose WIC participants are overwhelmingly minority, so we were not able to recruit significant numbers of non-Hispanic white mother/child dyads. Therefore, the generalizability of these results to other populations of families is limited. The results of the study also represent a natural experiment, so there is no comparable group for comparison. Reporting bias must also be a factor since the available data are based on self-report. Additionally, due to resource constraints, we only collected one $24 \mathrm{~h}$ recall, which may not necessarily characterize usual dietary intake. The strengths of the current study include a relatively large sample of lowincome, minority mothers and children who are at high risk for obesity and related sequelae.

These data provide a rare opportunity to evaluate the impact of a national policy shift in food assistance. Significant attention has been given to the effects of fiscal strategies, including both taxes and subsidies, on food consumption and weight outcomes ${ }^{(45)}$. Earlier WIC evaluation studies have consistently demonstrated the positive 
impact of WIC on pregnancy and birth outcomes ${ }^{(46-48)}$. However, the present study is one of the first investigations examining the impact of the revised food packages on home food availability and dietary intake. There is considerable interest in how the WIC food package revisions may positively influence access to foods more closely aligned with the 2005 Dietary Guidelines for Americans, overall diet quality and ultimately health outcomes. Our data provide important insight into how a change in public policy can affect individual behaviour in an urban minority population that makes up a sizeable portion of WIC recipients.

\section{Acknowledgements}

Sources of funding: This study was funded in part by the National Cancer Institute (RC1CA149400), R25CA067699, P50CA106743, P60MD003424 and the University of Illinois at Chicago Department of Kinesiology and Nutrition. Ethics: This research was reviewed and approved by the Institutional Review Board at University of Illinois at Chicago. Conflicts of interest: The authors have no conflicts of interest. Authors' contribution: A.M.O.-Y. conceptualized the study, selected measures, supervised baseline data collection and wrote the article content; A.K. prepared dietary data/measures and contributed to the article content; L.A.S. conducted the data analysis and interpretation, and contributed to the article content; S.J.P. performed the dietary data entry and contributed to the article content; L.B. oversaw the baseline data collection and contributed to the article content; S.B. assisted in conceptualizing the study and interpretation of the results, and contributed to the article content; M.L.B. provided guidance on data analysis and contributed to the article content; M.L.F. conceptualized the study, selected measures, supervised baseline data collection and contributed to the article content. Acknowledgements: The authors would like to thank Penny Roth at the Illinois Department of Human Services; Catholic Charities, particularly Angel Gutierrez and Doris Wilson for their support; the Chicago Department of Public Health; Near North Health Services Corporation; TCA Health Inc.; and the staff at the WIC clinic and food centres. They also truly appreciate the time that WIC participants gave them. Thanks are extended to Ms Guadalupe Compean for her technical assistance.

\section{References}

1. Ogden CL, Carroll MD, Curtin LR et al. (2010) Prevalence of high body mass index in US children and adolescents, 2007-2008. JAMA 303, 242-249.

2. Huang TTK \& Glass TA (2008) Transforming research strategies for understanding and preventing obesity. JAMA 300, 1811-1813.

3. Newby PK (2007) Introduction: moving forward the discussion on childhood obesity. J Law Med Ethics 35, 7-9.
4. Huang TT, Drewnosksi A, Kumanyika S et al. (2009) A systems-oriented multilevel framework for addressing obesity in the 21st century. Prev Chronic Dis 6, A82.

5. Herman DR, Harrison GG \& Jenks E (2006) Choices made by low-income women provided with an economic supplement for fresh fruit and vegetable purchase. $J \mathrm{Am}$ Diet Assoc 106, 740-744.

6. US Department of Agriculture, Food and Nutrition Service (2007) Special Supplemental Nutrition Program for Women, Infants and Children (WIC): Revisions in the WIC Food Packages; A Rule by the Food and Nutrition Service on 12/06/2007. Fed Reg 72, 68966-69032.

7. US Department of Agriculture (2011) WIC Food Packages Regulatory Requirements for WIC-Eligible Foods. http:// www.fns.usda.gov/wic/benefitsandservices/foodpkgregs.HTM (accessed December 2012).

8. Oliveira V \& Frazão E (2009) The WIC Program: Background, Trends, and Economic Issues, 2009 Edition. Economic Research Report no. ERR-73. Washington, DC: US Department of Agriculture, Economic Research Service; available at http://www.ers.usda.gov/publications/err73/ err73.pdf

9. Institute of Medicine (2010) Planning a WIC Research Agenda: Workshop Summary. Washington, DC: The National Academies Press.

10. Geller DM, Harrington M \& Huang G (2012) National Survey of WIC Participants II: Participant Characteristics Report. Alexandria, VA: US Department of Agriculture, Food and Nutrition Service, Office of Research and Analysis.

11. Andreyeva T, Luedicke J, Middleton AE et al. (2012) Positive influence of the revised Special Supplemental Nutrition Program for Women, Infants, and Children Food Packages on access to healthy foods. J Acad Nutr Diet 112, $850-858$.

12. Hillier A, McLaughlin J, Cannuscio CC et al. (2012) The impact of WIC food package changes on access to healthful food in 2 low-income urban neighborhoods. J Nutr Educ Behav 44, 210-216.

13. Andreyeva T, Middleton AE, Long MW et al. (2011) Food retailer practices, attitudes and beliefs about the supply of healthy foods. Public Health Nutr 14, 1024-1031.

14. Gittelsohn J, Laska MN, Andreyeva T et al. (2012) Small retailer perspectives of the 2009 Women, Infants and Children Program food package changes. Am J Health Behav 36, 655-665.

15. Ayala GX, Laska MN, Zenk SN et al. (2012) Stocking characteristics and perceived increases in sales among small food store managers/owners associated with the introduction of new food products approved by the Special Supplemental Nutrition Program for Women, Infants, and Children. Public Health Nutr 15, 1771-1779.

16. Jensen E (2012) Participation in the supplemental nutrition program for Women, Infants and Children (WIC) and breastfeeding: national, regional, and state level analyses. Matern Child Health J 16, 624-631.

17. Whaley SE, Ritchie LD, Spector P et al. (2012) Revised WIC food package improves diets of WIC families. J Nutr Educ Behav 44, 204-209.

18. Kong A, Odoms-Young AM, Schiffer LA et al. (2013) Racial/ ethnic differences in dietary intake among WIC families prior to food package revisions. J Nutr Educ Behav 45, 39-46.

19. Marin G, Sabogal F, Marin BV et al. (1987) Development of a short acculturation scale for Hispanics. Hisp J Behav Sci 9 , $183-205$.

20. Centers for Disease Control and Prevention (2011) A SAS Program for the CDC Growth Charts. http://www.cdc.gov/ nccdphp/dnpao/growthcharts/resources/sas.htm (accessed December 2012). 
21. Blumberg SJ, Bialostosky K, Hamilton WL et al. (1999) The effectiveness of a short form of the Household Food Security Scale. Am J Public Health 89, 1231-1234.

22. US Department of Agriculture, Economic Research Service (2012) Food Security in the US - Survey Tools. http:// www.ers.usda.gov/topics/food-nutrition-assistance/foodsecurity-in-the-us/survey-tools.aspx (accessed December 2012).

23. US Department of Agriculture (1998) Procedures for collecting 24-hour food recalls. http://www.csrees.usda. gov/nea/food/efnep/ers/documentation/24hour-recall.pdf (accessed December 2012).

24. Nutrition Coordinating Center, University of Minnesota (2009) NDS-R Nutrition Data System for Research Manual 2009. http://www.ncc.umn.edu/ndsrsupport/ndsrmanual 2009.pdf (accessed March 2013).

25. Smiciklas-Wright H, Mitchell DC, Mickle SJ et al. (2002) Foods Commonly Eaten in the United States: Quantities Consumed Per Eating Occasion and in a Day, 1994-1996. US Department of Agriculture NFS Report no. 96-5. http://www.ars.usda.gov/sp2userfiles/place/12355000/pdf/ portion.pdf (accessed December 2012).

26. Stamler J, Elliott P, Dennis B et al. (2003) INTERMAP: background, aims, design, methods, and descriptive statistics (nondietary). J Hum Hypertens 17, 591-608.

27. Miller PE, Mitchell DC, Harala PL et al. (2011) Development and evaluation of a method for calculating the Healthy Eating Index-2005 using the Nutrition Data System for Research. Public Health Nutr 14, 306-313.

28. US Department of Agriculture \& US Department of Health and Human Services (2005) Dietary Guidelines for Americans, 2005. Appendix A-2. USDA Food Guide. http:// www.health.gov/dietaryguidelines/dga2005/document/html/ appendixA.htm (accessed December 2012).

29. Cullen KW, Klesges LM, Sherwood NE et al. (2004) Measurement characteristics of diet-related psychosocial questionnaires among African-American parents and their 8- to 10-year-old daughters: results from the Girls' health Enrichment Multi-site Studies. Prev Med 38, Suppl., S34-S42.

30. Centers for Disease Control and Prevention (2009) Obesity prevalence among low-income, preschool-aged children United States, 1998-2008. MMWR Morb Mortal Wkly Rep 58, 769-773.

31. Center for Disease Control and Prevention (2009) NHANES 2007-2008. http://www.cdc.gov/nchs/nhanes/nhanes20072008/nhanes07_08.htm (accessed December 2012).

32. Center for Disease Control and Prevention (2012) Pediatric Nutrition Surveillance System (PedNSS). http://www.cdc. gov/pednss/ (accessed December 2012).

33. US Department of Agriculture \& US Department of Health and Human Services (2010) Dietary Guidelines for Americans, 2010, 7th ed, Washington, DC: US Government Printing Office; available at http://health.gov/dietaryguide lines/dga2010/dietaryguidelines2010.pdf

34. US Department of Agriculture (2012) MyPlate. http:// www.choosemyplate.gov/ (accessed December 2012).
35. O'Neil CE, Nicklas TA, Liu Y et al. (2009) Impact of dairy and sweetened beverage consumption on diet and weight of a multiethnic population of head start mothers. J Am Diet Assoc 109, 874-882.

36. Bermudez OI \& Gao X (2010) Greater consumption of sweetened beverages and added sugars is associated with obesity among US young adults. Ann Nutr Metab 57, 211-218.

37. Nicklas TA, Qu H, Hughes SO et al. (2011) Self-perceived lactose intolerance results in lower intakes of calcium and dairy foods and is associated with hypertension and diabetes in adults. Am J Clin Nutr 94, 191-198.

38. Karanja N, Lancaster KJ, Vollmer WM et al. (2007) Acceptability of sodium-reduced research diets, including the dietary approaches to stop hypertension diet, among adults with prehypertension and stage 1 hypertension. J Am Diet Assoc 107, 1530-1538.

39. Miura K, Giskes K \& Turrell G (2011) Contribution of takeout food consumption to socioeconomic differences in fruit and vegetable intake: a mediation analysis. J Am Diet Assoc 111, 1556-1562.

40. US Department of Health and Human Services \& US Department of Agriculture (2005) Dietary Guidelines for Americans, 2005, 6th ed. Washington, DC: US Government Printing Office.

41. Herman DR, Harrison GG, Afifi AA et al. (2008) Effect of a targeted subsidy on intake of fruits and vegetables among low-income women in the special supplemental nutrition program for Women, Infants, and Children. Am J Public Health 98, 98-105.

42. Fulkerson JA, Rydell S, Kubik MY et al. (2010) Healthy Home Offerings via the Mealtime Environment (HOME): feasibility, acceptability, and outcomes of a pilot study. Obesity (Silver Spring) 18, Suppl. 1, S69-S74.

43. Bryant M, Stevens J, Wang L et al. (2011) Relationship between home fruit and vegetable availability and infant and maternal dietary intake in African-American families: evidence from the exhaustive home food inventory. $J \mathrm{Am}$ Diet Assoc 111, 1491-1497.

44. Hopwood CJ, Flato CG, Ambwani S et al. (2009) A comparison of Latino and Anglo socially desirable responding. J Clin Psychol 65, 769-780.

45. Powell LM \& Chaloupka FJ (2009) Food prices and obesity: evidence and policy implications for taxes and subsidies. Milbank Q 87, 229-257.

46. Black MM, Cutts DB, Frank DA et al. (2004) Special Supplemental Nutrition Program for Women, Infants, and Children participation and infants' growth and health: a multisite surveillance study. Pediatrics 114, 169-176.

47. Bitler MP \& Currie J (2005) Does WIC work? The effects of WIC on pregnancy and birth outcomes. J Policy Anal Manage 24, 73-91.

48. Owen AL \& Owen GM (1997) Twenty years of WIC: a review of some effects of the program. J Am Diet Assoc 97, $777-782$. 